\title{
A Systematic Review on Bleeding Risk Scores' Accuracy after Percutaneous Coronary Interventions in Acute and Elective Settings
}

\author{
Crischentian Brinza ${ }^{1,+}$, Alexandru Burlacu ${ }^{1,2,3, *,+}$, Grigore Tinica ${ }^{1,2}$, Adrian Covic ${ }^{2,4}$ and Liviu Macovei ${ }^{1,2}$ \\ 1 Institute of Cardiovascular Diseases "Prof. Dr. George I.M. Georgescu", 700503 Iasi, Romania; \\ crischentian-branza@email.umfiasi.ro (C.B.); grigore.tinica@umfiasi.ro (G.T.); liviu.macovei@umfiasi.ro (L.M.) \\ 2 Faculty of Medicine, University of Medicine and Pharmacy "Grigore T Popa", 700115 Iasi, Romania; \\ adrian.covic@umfiasi.ro \\ 3 Medical Sciences Academy, 030167 Bucharest, Romania \\ 4 Nephrology Clinic, Dialysis, and Renal Transplant Center-'C.I. Parhon' University Hospital, \\ 700503 Iasi, Romania \\ * Correspondence: alexandru.burlacu@umfiasi.ro; Tel.: +40-7444-88580 \\ + Both authors contributed equally.
}

Citation: Brinza, C.; Burlacu, A.;

Tinica, G.; Covic, A.; Macovei, L. A Systematic Review on Bleeding Risk Scores' Accuracy after Percutaneous Coronary Interventions in Acute and Elective Settings. Healthcare 2021, 9, 148. https://doi.org/10.3390/ healthcare 9020148

Received: 19 December 2020

Accepted: 27 January 2021

Published: 2 February 2021

Publisher's Note: MDPI stays neutral with regard to jurisdictional claims in published maps and institutional affiliations.

Copyright: (c) 2021 by the authors. Licensee MDPI, Basel, Switzerland. This article is an open access article distributed under the terms and conditions of the Creative Commons Attribution (CC BY) license (https:/ / creativecommons.org/licenses/by/ $4.0 /)$.

\begin{abstract}
Dual antiplatelet therapy (DAT) is recommended for all patients undergoing percutaneous coronary intervention (PCI), as it significantly reduces the ischemic risk at the cost of increasing the incidence of bleeding events. Several clinical predictive models were developed to better stratify the bleeding risk associated with DAT. This systematic review aims to perform a literature survey of both standard and emerging bleeding risk scores and report their performance on predicting hemorrhagic events, especially in the era of second-generation drug-eluting stents and more potent P2Y12 inhibitors. We searched PubMed, ScienceDirect, and Cochrane databases for full-text studies that developed or validated bleeding risk scores in adult patients undergoing PCI with subsequent DAT. The risk of bias for each study was assessed using the prediction model risk of bias assessment tool (PROBAST). Eighteen studies were included in the present systematic review. Bleeding risk scores showed a modest to good discriminatory power with c-statistic ranging from 0.49 (95\% CI, $0.45-0.53)$ to 0.82 (95\% CI, 0.80-0.85). Clinical models that predict in-hospital bleeding events had a relatively good predictive performance, with c-statistic ranging from 0.70 ( $95 \% \mathrm{CI}, 0.67-0.72$ ) to 0.80 (95\% CI, 0.73-0.87), depending on the risk scores and major hemorrhagic event definition used. The knowledge and utilization of the current bleeding risk scores in appropriate clinical contexts could improve the prediction of bleeding events.
\end{abstract}

Keywords: bleeding risk scores; percutaneous coronary intervention; bleeding events; dual antiplatelet therapy; systematic review

\section{Introduction}

Dual antiplatelet therapy (DAT) has been a vital need once percutaneous coronary interventions (PCI) became available and different types of coronary stents were developed (bare-metal stents, BMS, and three generations of drug-eluting stents, DES). The risk of acute, subacute, late, or very late stent thrombosis represents a vital concern that is significantly reduced by implementing DAT. The ischemic risk was improved after the discovery and clinical use of new potent antiplatelet agents, P2Y12 antagonists, and third-generation drug-eluting stents, which carry a lower risk of thrombosis even after two years, compared to BMS [1-4]. DAT with Aspirin and a P2Y12 antagonist after percutaneous coronary angioplasty with BMS or DES is the standard of care recommended by all guidelines.

However, apart from reducing the incidence of ischemic events, DAT also increases the bleeding risk. As these patients are on the edge between ischemic and hemorrhagic events, careful examination of the patient risk profile is recommended. Nevertheless, patients may 
oftentimes exhibit a high risk of ischemic and bleeding events simultaneously, leading to a clinical and therapeutic dilemma. The duration of DAT is another issue frequently encountered in clinical practice, since the bleeding risk may exceed the ischemic risk after a certain time interval of DAT administration. This blurred line between switching to a single antiplatelet agent after DAT discontinuation and maintaining DAT is of considerable debate in clinical studies. Many bleeding risk scores were developed to assist in choosing the adequate therapeutic regimen and its duration, some of the scores being externally validated [5-8] (Table S1).

The American College of Cardiology (ACC)/American Heart Association (AHA) guidelines focusing on the duration of DAT were published before the development and validation of the Predicting Bleeding Complication in Patients Undergoing Stent Implantation and Subsequent Dual Antiplatelet Therapy (PRECISE-DAPT) risk score. Thus, the DAPT score was the only one available at that moment $[9,10]$. The position of the ACC/AHA Task Force is that the DAPT score may be useful in tailoring DAT duration after one year, giving more importance to the clinical judgment and careful evaluation of hemorrhagic and ischemic risk factors.

The European Society of Cardiology (ESC) and the European Association for CardioThoracic Surgery (EACTS) guidelines that focused on the DAT topic advocated for a personalized approach regarding bleeding and ischemic risks in the detriment of the generalized strategy. The task force recommends (class IIB, level of evidence A) the use of dedicated scores to evaluate a patient's risk profile to establish the duration of DAT in different clinical settings. PRECISE-DAPT and DAPT are the recommended risk scores by the Task Force [11]. According to the Task Force, patients presenting with CCS treated with DES or BMS can benefit from standard or long-term DAT (6 months or more) if they are not at increased bleeding risk (PRECISE-DAPT $<25)$ or short DAT $(1-3$ months) if they are at high risk of bleeding (PRECISE-DAPT $\geq 25$ ). Patients with ACS who underwent PCI with DES or BMS with a high bleeding risk (PRECISE-DAPT $\geq 25$ ) could be treated with a short DAT regimen (6 months), and those with non-high bleeding risk (PRECISE-DAPT $<25$ ) could benefit from a longer DAT duration (12 months or more). After 12 months of DAT in patients without hemorrhagic events, DAPT score can be further used to tailor DAT duration.

However, the lack of a perfect risk score with a substantial predictive value led to further research and development of clinical models in addition to PRECISE-DAPT and DAPT scores: Patterns of Non-Adherence to Anti-Platelet Regimen in Stented Patients (PARIS), Can Rapid risk stratification of Unstable angina patients Suppress ADverse outcomes with Early implementation of the ACC / AHA guidelines (CRUSADE), The Academic Research Consortium for high bleeding risk (ARC-HBR), Acute Catheterization and Urgent Intervention Triage strategY-Harmonizing Outcomes with Revascularization and Stents in Acute Myocardial Infarction (ACUITY-HORIZONS), Bleeding complications in a Multicenter registry of patients discharged with a diagnosis of Acute Coronary Syndrome (BleeMACS), ACTION, Mehran.

In the last few years, new clinical models were developed and were validated in various clinical scenarios to better predict hemorrhagic events in patients treated with DAT following PCI. The objective of this updated systematic review was to search the literature for classic and newer bleeding risk scores and their predictive performance, especially in the era of second-generation DES and more potent P2Y12 inhibitors.

\section{Materials and Methods}

The systematic review was conducted according to Preferred Reporting Items for Systematic Review and Meta-Analysis (PRISMA) checklist [12].

\subsection{Data Sources}

The search was performed in two steps (March 2020 and November 2020) in PubMed, ScienceDirect and Cochrane databases, using the following terms: "PRECISE-DAPT", 
"DAPT", “PARIS", “ACUITY”, “CRUSADE”, “ARC-HBR", “BleeMACS”, “bleeding risk score", "dual antiplatelet therapy", "stratifying bleeding risk", "percutaneous coronary intervention", "major bleeding", and "predictive value". The search was restricted to trials involving humans and published in English.

\subsection{Study Selection}

Studies were eligible if they reported original data regarding the discriminatory power of the risk scores used to predict bleeding events associated with DAT, as the primary or secondary outcome in adult patients undergoing PCI for acute or chronic coronary syndromes (ACS and CCS, respectively). Several exclusion criteria were established: studies available only in abstract, the outcome of interest was not reported, meta-analyses, bleeding events were not defined as minor or major according to The Bleeding Academic Research Consortium (BARC), The Thrombolysis in Myocardial Infarction (TIMI), Global Use of Strategies to Open Occluded Coronary Arteries (GUSTO) or other definitions based on local expertise. In addition, studies that focused exclusively on triple antithrombotic therapy were excluded.

\subsection{Data Extraction}

The following data were extracted from each study: design, the number of patients included, the clinical setting, the evaluated bleeding risk score and its discriminatory power, the criteria used in grading bleeding events, the proportion of major bleeding events, and the time interval. Disagreements were resolved by consensus. When available, data are presented as percentages, ranges of variation, mean or median values, c-statistic/Area Under the Receiver Operating Characteristics (AUC/AUROC), and confidence intervals (CIs). In addition, when possible, the sensitivity, specificity, and accuracy of the bleeding risk scores are reported.

\subsection{Outcomes}

We assessed the predictive performance of different bleeding risk scores reported in clinical trials that included patients with DAT after PCI in an in-hospital setting or following discharge after hemorrhagic events.

\subsection{Risk of Bias}

The risk of bias and applicability concern for each study were appraised using the Prediction model Risk Of Bias Assessment Tool (PROBAST), which was designed for diagnostic and prognostic clinical models in the setting of development or validation [13]. PROBAST checklist comprises four domains (participants, predictors, outcome, analysis) with different signaling questions, which evaluate the overall risk of bias and applicability.

\section{Results}

Our search in databases identified 4647 citations. After screening for duplicates and reviewing the titles and abstracts, 4605 citations were excluded. Of the remaining 42 studies, one meta-analysis and six abstracts were excluded. An additional 17 studies were excluded because inclusion criteria were not met or due to the inability to extract data, leaving 18 trials included (Figure 1).

Each study and population characteristics are summarized in Table 1.

Of 18 studies, eight were single-center: South Korea [14], Spain [15-17], Switzerland [18], USA [19], China [20], Sweden [21], and ten were performed in multiple centers [22-31]. Two studies evaluated the risk scores for predicting in-hospital bleeding events $[16,17]$, while the others assessed the clinical models for predicting hemorrhagic events associated with long-term DAT ( $\leq 1$ year-eight studies and $>1$ year-eight studies). 
Table 1. General characteristics of studies included in present systematic review.

\begin{tabular}{|c|c|c|c|c|c|c|c|c|c|}
\hline \multirow{2}{*}{ Study } & \multirow{2}{*}{ Type of Study } & \multirow{2}{*}{ Risk Score } & \multirow{2}{*}{ Enrollment (Time, Place) } & \multirow{2}{*}{$\begin{array}{l}\text { Number of } \\
\text { Patients }\end{array}$} & \multirow{2}{*}{ Clinical Setting } & \multirow{2}{*}{$\begin{array}{c}\text { Age } \\
\text { Median/Mean }\end{array}$} & \multicolumn{3}{|c|}{ Bleeding Events } \\
\hline & & & & & & & Number (\%) & Definition & Time \\
\hline \multirow{3}{*}{$\begin{array}{l}\text { Costa et al., } \\
2017[22]\end{array}$} & \multirow{3}{*}{ RTS } & $\begin{array}{l}\text { PRECISE-DAPT } \\
\text { (derivation cohort) }\end{array}$ & $\begin{array}{l}139 \text { different clinical sites } \\
\text { from } 12 \text { countries } \\
\text { worldwide }\end{array}$ & 14,963 & \multirow{3}{*}{$\mathrm{PCI}+$ stent } & 65.0 & $218(1.5)$ & $\begin{array}{l}\text { TIMI major or minor } \\
\text { bleeding }\end{array}$ & 1 year \\
\hline & & $\begin{array}{l}\text { PRECISE-DAPT } \\
\text { (validation } \\
\text { cohort-PLATO) }\end{array}$ & 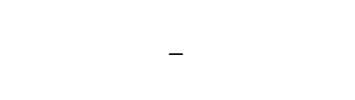 & 8595 & & 61.0 & $145(1.7)$ & $\begin{array}{l}\text { TIMI major or minor } \\
\text { bleeding }\end{array}$ & 1 year \\
\hline & & $\begin{array}{l}\text { PRECISE-DAPT } \\
\text { (validation } \\
\text { cohort-BernPCI) }\end{array}$ & $\begin{array}{l}\text { Switzerland, between } 23 \\
\text { February 2009, and } 31 \\
\text { December } 2014\end{array}$ & 6172 & & 67.2 & $\begin{array}{c}94 \\
(1.5)\end{array}$ & $\begin{array}{l}\text { TIMI major or minor } \\
\text { bleeding }\end{array}$ & 1 year \\
\hline $\begin{array}{l}\text { Choi et al., } \\
2018 \text { [14] }\end{array}$ & RTS & $\begin{array}{l}\text { PRECISE-DAPT } \\
\text { ACUITY } \\
\text { CRUSADE }\end{array}$ & $\begin{array}{l}\text { Korea, between November } \\
2008 \text { and November } 2015\end{array}$ & 904 & $\mathrm{PCI}+$ stent & 65.5 & $\begin{array}{l}119(13.2) \\
80(8.8) \\
154(17)\end{array}$ & $\begin{array}{l}\text { TIMI major or minor } \\
\text { bleeding } \\
\text { GUSTO moderate or } \\
\text { severe } \\
\text { BARC } \geq 3 \mathrm{a}\end{array}$ & 1 year \\
\hline $\begin{array}{l}\text { Abu-Assi et al., } \\
2018 \text { [15] }\end{array}$ & RTS & $\begin{array}{l}\text { PRECISE-DAPT } \\
\text { PARIS }\end{array}$ & $\begin{array}{l}\text { Spain, between January } \\
2012 \text { and March } 2015\end{array}$ & 1926 & $\mathrm{ACS}+\mathrm{PCI}+$ stent & 65.1 & $\begin{array}{l}136(7.1) \\
53(2.8)\end{array}$ & $\begin{array}{l}\text { BARC type } 2,3 \text { or } 5 \\
\text { BARC type } 3 \text { or } 5\end{array}$ & 1 year \\
\hline $\begin{array}{l}\text { Ueki et al., } \\
2020 \text { [18] }\end{array}$ & OBS & ARC-HBR & $\begin{array}{l}\text { Switzerland, between } \\
\text { January } 2009 \text { and } \\
\text { December } 2016\end{array}$ & 12,121 & $\mathrm{PCI}+$ stent & $\begin{array}{c}75.5 \\
\text { HBR } \\
62.8 \\
\text { non-HBR }\end{array}$ & $\begin{array}{c}304(6.4) \mathrm{HBR} \\
140(1.9) \\
\text { non-HBR }\end{array}$ & BARC type 3 or 5 & 1 year \\
\hline \multirow[b]{2}{*}{ Yeh et al., 2016 [23] } & \multirow[b]{2}{*}{ RTS } & $\begin{array}{l}\text { DAPT (derivation } \\
\text { cohort) }\end{array}$ & $\begin{array}{l}11 \text { countries, from August } \\
2009 \text { to May } 2014\end{array}$ & 11,648 & \multirow[b]{2}{*}{$\mathrm{PCI}+$ stent } & 61.3 & $215(1.8)$ & \multirow[b]{2}{*}{$\begin{array}{l}\text { GUSTO moderate or } \\
\text { severe }\end{array}$} & \multirow[b]{2}{*}{$12-30 \mathrm{~m}$} \\
\hline & & $\begin{array}{l}\text { DAPT (validation } \\
\text { cohort- } \\
\text { PROTECT) }\end{array}$ & $\begin{array}{l}36 \text { countries, from June } \\
2007 \text { through July } 2014\end{array}$ & 8136 & & 62.0 & $37(0.5)$ & & \\
\hline \multirow{2}{*}{$\begin{array}{l}\text { Baber et al., } \\
2016[24]\end{array}$} & \multirow{2}{*}{ OBS } & $\begin{array}{l}\text { PARIS (derivation } \\
\text { cohort) }\end{array}$ & \multirow{2}{*}{$\begin{array}{l}\text { United States and Europe } \\
\text { between July } 2009 \text { and } \\
\text { December } 2010\end{array}$} & 4190 & \multirow{2}{*}{$\begin{array}{c}\text { PCI }+\underset{\text { drug eluting }}{\text { stent }} \\
\text { drent }\end{array}$} & $\begin{array}{l}67.8 \mathrm{MB} \\
63.6 \text { no MB }\end{array}$ & $133(3.3)$ & \multirow{2}{*}{$\begin{array}{c}\text { BARC type } 3 \text { or } 5 \\
\text { Bleeding requiring } \\
\text { hospitalization or } \\
\text { transfusion }\end{array}$} & \multirow{2}{*}{2 year } \\
\hline & & $\begin{array}{l}\text { PARIS (validation } \\
\text { cohort) }\end{array}$ & & 8130 & & & $296(3.6)$ & & \\
\hline $\begin{array}{l}\text { Bianco et al., } \\
2019[25]\end{array}$ & RTS & $\begin{array}{l}\text { PRECISE-DAPT } \\
\text { PARIS }\end{array}$ & $\begin{array}{l}12 \text { European centers from } \\
\text { January } 2012 \text { to December } \\
2016 \text { (RENAMI registry) }\end{array}$ & 4424 & $\mathrm{ACS}+\mathrm{PCI}+$ stent & 60.9 & $83(1.88)$ & BARC type 3 or 5 & $14 \mathrm{~m}$ \\
\hline
\end{tabular}


Table 1. Cont.

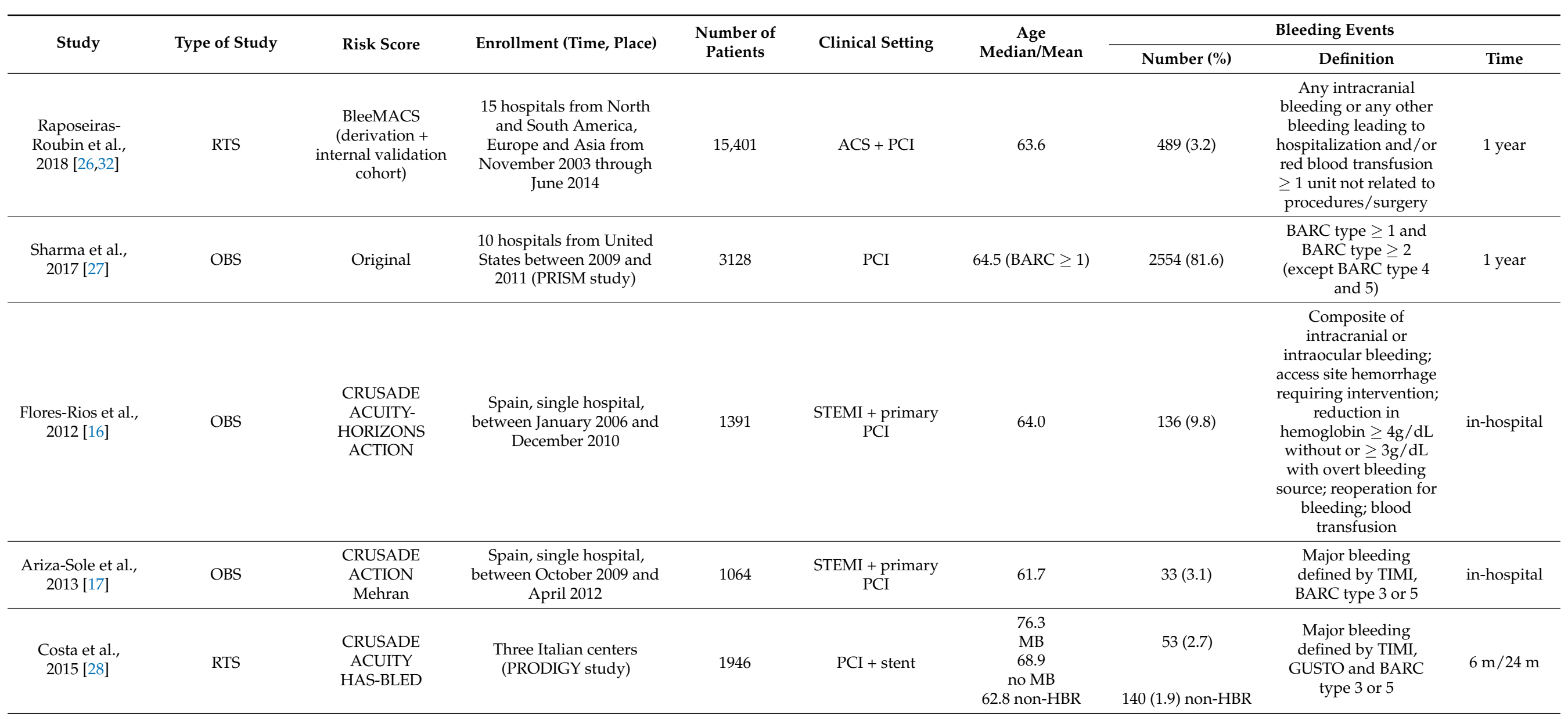


Table 1. Cont.

\begin{tabular}{|c|c|c|c|c|c|c|c|c|c|}
\hline \multirow{2}{*}{ Study } & \multirow{2}{*}{ Type of Study } & \multirow{2}{*}{ Risk Score } & \multirow{2}{*}{ Enrollment (Time, Place) } & \multirow{2}{*}{$\begin{array}{l}\text { Number of } \\
\text { Patients }\end{array}$} & \multirow{2}{*}{ Clinical Setting } & \multirow{2}{*}{$\begin{array}{c}\text { Age } \\
\text { Median/Mean }\end{array}$} & \multicolumn{3}{|c|}{ Bleeding Events } \\
\hline & & & & & & & Number (\%) & Definition & Time \\
\hline $\begin{array}{l}\text { Choi et al., } \\
2020[29]\end{array}$ & $\begin{array}{l}\text { Analy-sis } \\
\text { from RCT }\end{array}$ & PRECISE-DAPT & $\begin{array}{l}31 \text { centers in Republic of Korea } \\
\text { (SMART-DATE trial) }\end{array}$ & 2712 & $\mathrm{ACS}+\mathrm{PCI}$ & $\begin{array}{c}74.0 \mathrm{HBR} \\
57.7 \text { non-HBR }\end{array}$ & $\begin{array}{c}10(1.5) \mathrm{HBR} \\
6(0.3) \text { non-HBR }\end{array}$ & BARC type $3-5$ & $18 \mathrm{~m}$ \\
\hline $\begin{array}{l}\text { Kawashima } \\
\text { et al., 2020 } \\
\text { [30] }\end{array}$ & $\begin{array}{l}\text { Analy-sis } \\
\text { from RCT }\end{array}$ & $\begin{array}{l}\text { PRECISE-DAPT } \\
\text { CRUSADE } \\
\text { ACUITY }\end{array}$ & $\begin{array}{l}130 \text { hospitals in } 18 \text { countries } \\
\text { between July } 2013 \text { to } \\
\text { November } 2015\end{array}$ & 14,709 & $\mathrm{PCI}$ & 64.6 & - & BARC type 3 or 5 & $30 \mathrm{~d}$ \\
\hline $\begin{array}{l}\text { Cao et al., } \\
2020[19]\end{array}$ & OBS & ARC-HBR & $\begin{array}{c}\text { Tertiary care center in New York, } \\
\text { between January } 2014 \text { and } \\
\text { December } 2017\end{array}$ & 9623 & $\mathrm{PCI}+$ stent & $\begin{array}{c}71.7 \mathrm{HBR} \\
61.8 \text { non-HBR }\end{array}$ & $\begin{array}{c}390(9.1) \mathrm{HBR} \\
172(3.2) \\
\text { non-HBR }\end{array}$ & $\begin{array}{l}\text { Bleeding event requiring } \\
\text { either hospitalization or } \\
\text { blood transfusion }\end{array}$ & 1 year \\
\hline $\begin{array}{l}\text { Song et al., } \\
2018 \text { [20] }\end{array}$ & OBS & $\begin{array}{l}\text { DAPT } \\
\text { PARIS }\end{array}$ & $\begin{array}{l}\text { Single hospital in China, from } 1 \\
\text { January to } 31 \text { December } 2013\end{array}$ & 6088 & $\mathrm{PCI}+\mathrm{DES}$ & 58.3 & $30(0.50)$ & BARC type 3 or 5 & 2 year \\
\hline $\begin{array}{l}\text { Ueda et al., } \\
2018[21]\end{array}$ & OBS & DAPT & $\begin{array}{l}\text { Sweden, between } 1 \text { January } 2006 \\
\text { and } 31 \text { December } 2013\end{array}$ & 41,101 & PCI + stent & $\begin{array}{l}61.2 \text { high DAPT } \\
\text { score }\end{array}$ & $311(0.75)$ & GUSTO moderate or severe & $30 \mathrm{~m}$ \\
\hline $\begin{array}{l}\text { Gragnano } \\
\text { et al., } \\
2020[31]\end{array}$ & $\begin{array}{l}\text { Analy-sis } \\
\text { from RCT }\end{array}$ & $\begin{array}{l}\text { PRECISE-DAPT } \\
\text { (GLOBAL } \\
\text { LEADERS trial) } \\
\text { PRECISE-DAPT } \\
\text { (GLASSY trial) }\end{array}$ & $\begin{array}{l}130 \text { sites in } 18 \text { countries } \\
\text { Sub-study of GLOBAL } \\
\text { LEADERS trial with patients } \\
\text { enrolled at the } 20 \text { highest } \\
\text { recruiting sites }\end{array}$ & 14,928 & $\mathrm{PCI}+\mathrm{DES}$ & $\begin{array}{c}62.5 \text { low } \\
\text { PRECISE-DAPT } \\
75.0 \text { high } \\
\text { PRECISE-DAPT } \\
62.7 \text { low } \\
\text { PRECISE-DAPT } \\
75.9 \text { high } \\
\text { PRECISE-DAPT }\end{array}$ & $\begin{array}{c}163(2.18) \\
\text { control group }\end{array}$ & BARC type 3 or 5 & $\begin{array}{l}1 \text { year and } \\
2 \text { year }\end{array}$ \\
\hline
\end{tabular}

$\mathrm{RTS}=$ retrospective OBS = observational $\mathrm{RCT}$ = randomized controlled trial; $\mathrm{HBR}=$ high bleeding risk $\mathrm{MB}$ = major bleeding. 


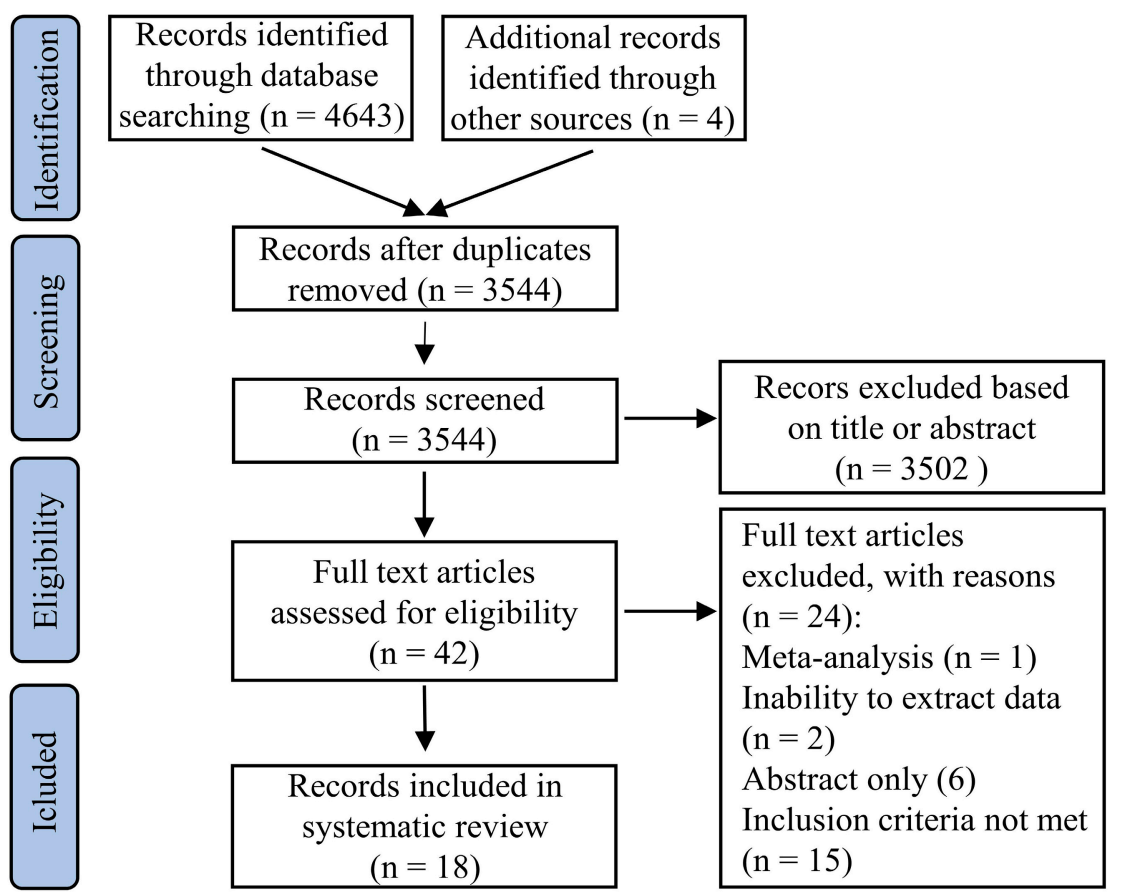

Figure 1. Flow diagram of the studies selection for inclusion in the systematic review.

The most often used bleeding definition was provided by BARC, which was followed by TIMI and GUSTO. Two studies defined major hemorrhagic events based on local expertise [16,26]. Six studies [15-17,25,26,29] evaluated the performance of bleeding risk scores in the context of ACS with PCI and subsequent DAT, including two studies focused on ST-elevation myocardial infarction (STEMI) [16,17].

Essential differences were reported regarding the P2Y12 antagonist used as part of DAT. In this regard, Clopidogrel was the most investigated drug in studies. Seven clinical trials used more potent P2Y12 antagonists (Ticagrelor or Prasugrel) to a greater extent $[15,18,19,23,25,29,30]$. There were differences in the type of stent used (DES or BMS) and the proportion of patients needing oral anticoagulant therapy for the long-term.

The comparative predictive performances described as the discriminatory power (c-statistic) of the bleeding risk scores, as reported in each study, are illustrated in Table S2. Overall, the bleeding risk scores demonstrated a modest to good discriminatory power, with c-statistic ranging from 0.49 (95\% CI, 0.45-0.53) to 0.82 (95\% CI, 0.80-0.85).

The highest c-statistic of 0.82 was recorded by Choi et al. [14], in the case of the PRECISE-DAPT risk score when bleeding events were defined by GUSTO criteria. Of note, in the derivation cohort of PRECISE-DAPT bleeding risk score, and validation cohortsPLATelet inhibition and patient Outcomes (PLATO) trial and BernPCI registry [22], the cstatistic was significantly lower $(0.73,0.70$, and 0.66 respectively). The PRECISE-DAPT score was also validated by Choi et al. [29] in patients with ACS with a similar prediction power, and by Kawashima et al. [30], who reported a lower c-statistic value (0.648). Gragnano et al. [31] assessed the classic PRECISE-DAPT score's performance and the four-item PRECISE-DAPT score performance, which was recently developed. The c-statistic was similar at one year and two years, ranging between 0.60 and 0.66 .

Two studies [23,24] developed and validated DAPT and PARIS risk scores for predicting bleeding events in patients with long-term DAT, beyond one year. DAPT and PARIS bleeding risk scores showed a modest discrimination power in derivation (c-statistic 0.68 and 0.75 respectively) and validation cohorts (c-statistic 0.64 for both scores). However, the population covered was different because the PARIS study included only patients who underwent PCI with DES. The DAPT score was also evaluated by Ueda et al. [21], in a large cohort of patients-Swedish Web-system for Enhancement and Development of Evidence-based care in Heart disease Evaluated According to Recommended Ther- 
apies (SWEDEHEART) registry, but the c-statistic was unsatisfactory (0.49). However, Song et al. [20] reported an excellent prediction power regarding DAPT score (0.71), but there were a few hemorrhagic events.

Abu-Assi et al. [15] and Bianco et al. [25] comparatively appraised the predictive performance of PRECISE-DAPT and PARIS risk scores in case of patients with ACS treated with PCI. In the former study, the authors reported a similar discrimination power for both risk scores (c-statistic 0.73), but the discrimination power was lower in the latter study, especially in the PARIS score (c-statistic 0.653 for PRECISE-DAPT score and 0.593 for PARIS score).

ARC-HBR, a newer bleeding risk score, was validated by Ueki et al. [18] and Cao et al. [19] in patients treated with DAT following PCI with stenting. This bleeding risk score had a similar discrimination power (respectively, c-statistic 0.67 and 0.68 ).

BleeMACS is another bleeding risk score developed and validated internally and externally by Raposeiras-Roubin et al. [26,32]. In large derivation and validation cohorts, the authors reported a modest predictive power for bleeding events (c-statistic 0.71 in derivation cohort). This score was externally validated in SWEDE-HEART registry, with a c-statistic of 0.65 in the case of patients who underwent PCI.

Another study [28] assessed the role of CRUSADE, ACUITY, and HAS-BLED scores in predicting bleeding events associated with DAT for up to 24 months. The authors noted a similar discrimination power for CRUSADE and ACUITY risk scores (c-statistic 0.71 and 0.68 respectively), which was lower for the HAS-BLED score (c-statistic 0.63$)$. However, a small number of bleeding events $(53,2.7 \%)$ were observed during follow-up, limiting the study results.

Sharma et al. [27], developed and internally validated an original bleeding risk score for patients with PCI and subsequent DAT. The score achieved a modest performance, with a c-statistic of 0.67 . Results are limited by the definition of bleeding used, BARC type $\geq 1$, along with the exclusion of BARC type 5 .

Two studies [16,17], which evaluated the performance of bleeding risk scores in predicting in-hospital hemorrhagic events, showed concordant results, with a c-statistic value of 0.77 and 0.80 , respectively, for the CRUSADE score. In addition, the ACTION risk score's predictive performance was similar in both studies (c-statistic 0.78 and 0.75 , respectively) but was slightly lower in the case of ACUITY-HORIZONS score (c-statistic 0.70). The clinical setting is essential, as both studies included patients with STEMI who underwent primary PCI.

Risk of bias and concern regarding applicability were assessed using the PROBAST checklist [13] designed for clinical models' development and validation studies, and results are reported in Table S3. Overall, there was a high risk of bias, given that most studies are observational and retrospective. Most studies had low concern regarding applicability, as patients, predictors, and outcomes correspond to criteria of selection and inclusion in the present systematic review.

\section{Discussion}

Once DAT became a mandatory therapeutic regimen following PCI, the rate of ischemic events was significantly reduced at the cost of increased incidence of bleeding events. ACC/AHA, ESC, and EACTS recommend a personalized approach and careful evaluation of each patient's ischemic and bleeding risks. Tailoring duration of DAT is one of the most critical concerns, as the bleeding risk can exceed the ischemic risk in certain circumstances. For this purpose, the DAPT risk scores are endorsed by ACC/AHA, ESC, and EACTS, which recommend the clinical use of both PRECISE-DAPT and DAPT scores.

However, with the advent of more potent P2Y12 inhibitors and new generations of stents, current research is geared toward developing new risk scores or updating the validity of existing scores in the present-day clinical settings.

The PRECISE-DAPT score was developed and validated in large cohorts of patients [22] who underwent PCI with stent implantation. This score helps adjust the duration 
of DAT (short versus standard/long). Nevertheless, Clopidogrel was the most used P2Y12 antagonist ( $88 \%$ ) in the study as part of DAT, thus raising concern regarding applicability in the context of more potent P2Y12 inhibitors, which are widely prescribed. In addition, patients requiring triple antithrombotic medication were excluded from the study. Choi et al. [29] validated the PRECISE-DAPT score in a cohort of patients, which is somewhat closer to contemporary patients (almost all received DES, but more potent P2Y12 were prescribed to only $22 \%$ of non-HBR patients). Moreover, Gragnano et al. [31] validated both classic PRECISE-DAPT score and the four-item PRECISE-DAPT score (recently developed) in all-comer patients receiving DES reported a similar prediction power.

The DAPT score combines ischemic and bleeding risks, and American and European guidelines recommend tailoring the duration of DAT after 12 months of treatment (up to 30 months in long-term DAT). The derivation and validation cohorts [23] included only patients who had not experienced ischemic or hemorrhagic events during the first year, but those with long-term anticoagulant therapy were excluded. Clopidogrel or Prasugrel was administered as a P2Y12 antagonist. In addition, it also included patients who received either BMS or DES (89.3\% of patients with bleeding events and $85.4 \%$ of patients without bleeding events). However, the DAPT score is not suitable for patients with a high risk of bleeding as a criterion for selecting BMS. That is why the DAPT score is addressed to carefully selected patients, comparable to those included in the derivation and validation studies.

The PARIS bleeding risk score [24] was developed and validated in cohorts of patients who underwent PCI with DES from Europe and the USA, but its recommendation by guidelines in stratifying bleeding risk is unclear. The inclusion of patients treated with triple antithrombotic therapy at discharge is a possible advantage of this study. The PARIS risk score is appropriate for a limited group of patients, as those treated with BMS were excluded, and Clopidogrel was the P2Y12 antagonist used in the majority of cases. Unsurprisingly, long-term oral anticoagulation was associated with an increased incidence of hemorrhagic events and was included in the final prediction model, in contrast to the DAPT study, which does not cover this clinical area. In addition, the PARIS study provided a score predicting the risk of ischemic events, which could improve along with the bleeding risk score the selection of patients in whom extending the duration of DAT after one year is useful and less harmful.

Abu-Assi et al. [15] attempted to compare the predictive performance of PARIS and PRECISE-DAPT bleeding risk scores in a cohort of patients with ACS and PCI from Spain. The particularities of this study are represented by a more significant proportion of patients treated with triple antithrombotic therapy at discharge $(8.2 \%$ in comparison to PARIS derivation cohort-4.8\% and PRECISE-DAPT study- $0 \%$ ) and a greater extent of Ticagrelor prescribed (22.9\% versus PRECISE-DAPT cohort-3.9\%). In addition, patients treated with DES, as well as those treated with BMS, were included. Both scores had a modest performance for predicting one-year hemorrhagic events, with a similar c-statistic value (0.73).

PRECISE-DAPT and PARIS bleeding risk scores were externally validated in another study by Bianco et al. [25] in patients with ACS and PCI with stenting. However, the cohort was different. As part of DAT, Aspirin in addition to Ticagrelor (61\%) or Prasugrel (39\%) were prescribed, thus excluding Clopidogrel from the therapeutic regimen. In addition, the proportion of patients treated with DES was greater (93\%) than the proportion of patients treated with BMS (7\%), which was somewhat different in comparison to PARIS derivation and validation cohorts, when only DES were used. This study's population is closer to the contemporary patients in the context of availability of more potent P2Y12 inhibitors, slightly favoring PRECISE-DAPT score in stratifying bleeding risk.

Ueki et al. [18] validated a new risk score, ARC-HBR, which was designed for patients who underwent PCI with stent implantation. Potent P2Y12 inhibitors (Ticagrelor or Prasugrel) were prescribed more frequently in the case of patients without a high risk of bleeding (52.5\%) than in those with a high risk of hemorrhagic events $(24.7 \%)$. On the 
one hand, the ARC-HBR score had a modest discriminatory power for bleeding events (c-statistic 0.69 ), with good sensitivity $(68.5 \%)$ and negative predictive value $(98.1 \%)$; on the other hand, specificity was lower $(61.7 \%)$ with a poor positive predictive value $(6.4 \%)$. ARC-HBR score was also validated by Cao et al. [19], in a contemporary real-world cohort of patients (almost all received DES), including those requiring anticoagulant drugs.

Raposeiras-Roubin et al. [26] developed and internally validated BleeMACS scores in a large cohort of patients in ACS with PCI and subsequent DAT involving ten different North American countries, South America, Europe, and Asia. The BleeMACS score was also externally validated in the SWEDE-HEART registry, including 96,239 consecutive patients with ACS. The discrimination power for bleeding events was slightly lower in the SWEDE-HEART cohort (c-statistic 0.65 for patients with PCI and 0.63 in those without PCI) than in the derivation cohort. Furthermore, the BleeMACS score's performance was tested across different types of DAT in the external validation cohort. Hemorrhagic events' discrimination power was similar for Aspirin plus Clopidogrel and Aspirin plus Ticagrelor (c-statistic 0.65).

Moreover, the role of BleeMACS score in stratifying bleeding events was evaluated in patients treated with different anticoagulant regimens in the SWEDE-HEART registry. The discriminatory power of BleeMACS score decreased in patients treated with triple antithrombotic therapy (c-statistic 0.60 ) but was slightly higher in patients treated with dual antithrombotic therapy, with oral anticoagulant and an antiplatelet agent (c-statistic 0.69). The study's evident strength is represented by the large number of patients from different countries included in derivation and validation cohorts. In addition, the fact that the performance of the BleeMACS score in predicting bleeding events was evaluated in different antithrombotic therapies represents a clear advantage.

The CRUSADE risk score was initially developed and validated for predicting inhospital bleeding events in patients with NSTEMI [33], ACUITY-HORIZONS, and ACTION scores-in patients with both STEMI and NSTEMI [34,35]. All three bleeding risk scores were evaluated by Flores-Rios et al. [16] for predicting in-hospital bleedings in patients with STEMI and primary PCI from a single center in Spain. All patients in the cohort received a loading dose of Clopidogrel and Aspirin followed by a maintenance dose, limiting current therapeutic regimens' applicability with more potent P2Y12 antagonists. The authors also advocated for intravenous treatment with glycoprotein IIb-IIIa inhibitors (Abciximab), which is a strategy that could modify the bleeding risk profile. Considering all these factors in interpreting the results, CRUSADE and ACTION scores performed better in predicting in-hospital bleeding events than ACUITY-HORIZONS score.

The CRUSADE score was validated by Ariza-Sole et al. [17] in patients with STEMI who underwent primary PCI. Patients with chronic oral anticoagulation were excluded, and none of the participants received novel P2Y12 inhibitors. According to CRUSADE criteria, when hemorrhagic events were defined, the CRUSADE score had a better discriminatory power in predicting bleeding events than ACTION and Mehran scores, which is a difference that did not maintain when BARC criteria defined hemorrhagic events. The authors also observed that the CRUSADE score had a higher c-statistic value $(0.86,95 \%$ CI $0.77-0.96)$ in patients treated with glycoprotein IIb-IIIa inhibitors, and patients had a higher rate of major in-hospital bleeding events. Moreover, the CRUSADE score's predictive power was similar in patients who underwent angiography using both the transradial or transfemoral approach. However, a low incidence of bleeding events during follow-up (33 patients, $3.1 \%$ ) could be a source of bias in interpreting the results.

Costa et al. [28] evaluated the value of three risk scores, CRUSADE, ACUITY, and HAS-BLED, to predict hemorrhagic events in patients who underwent PCI with stenting, which was treated with short-term (6 months) or long-term (24 months) DAT. This is a non-classic indication for CRUSADE and ACUITY scores, as both were developed and validated for the prediction of in-hospital hemorrhagic events, not for out of hospital bleedings. The HAS-BLED score is also approved for stratifying bleeding risk in patients who need anticoagulant therapy, not in those with DAT. Nevertheless, CRUSADE and 
ACUITY scores had a better predictive performance for bleeding events than HAS-BLED. However, the DAT regimen consisted of Aspirin plus Clopidogrel, and none of the patients received novel P2Y12 inhibitors. The results are limited by fewer hemorrhagic events reported (53 patients, $2.7 \%$ ).

Choi et al. [14] evaluated the predictive power of PRECISE-DAPT, ACUITY, and CRUSADE bleeding risk scores in a cohort of patients from South Korea who underwent PCI with stent implantation and subsequently DAT. Patients treated with oral anticoagulants and those with severe chronic renal failure were excluded. In addition, Clopidogrel was prescribed with predilection (94.9\%), instead of Ticagrelor (0.8\%) and Prasugrel (4.3\%). Although ACUITY and CRUSADE risk scores were not developed to predict long-term bleeding events, the discriminatory power was similar to that reported for PRECISEDAPT score.

Although American and European guidelines recommend only DAPT and PRECISEDAPT scores, both have limitations because of differences between the cohort of patients, type of DAT, type of stent used in studies, and real-world patients. Given that there is a trend of high individualization in bleeding risk stratification in the case of patients treated with DAT, alternative risk scores validated in large cohorts of patients could be applied in a particular clinical scenario that is the closest to that analyzed in studies. Furthermore, a concern is raised about the applicability of bleeding risk scores in elderly patients. In this regard, Pavasini et al. [36] reported a similar efficiency of PRECISE-DAPT, PARIS, and BleeMACS risk scores, suggesting that these scores could also be used in older adults.

That is why all available data from patients should be carefully analyzed before using a prediction score, without neglecting the clinical judgment. None of the scores has a perfect prediction performance. Moreover, a novel trend is represented by the shortening of DAT duration [37] followed by treatment with a single antiplatelet agent reported by studies, with the same ischemic risk but with an improved hemorrhagic risk [38-41], which may change the bleeding profile of the patients in the future.

\section{Conclusions}

The existence of so many bleeding risk scores denotes the imperious need for a very accurate clinical model that could help adjust the type and duration of DAT to reduce the ischemic risk efficiently without increasing the bleeding risk. Each score has its benefits and limits derived from the characteristics of the development and validation cohorts and could be applied to a specific patient, in a particular clinical context, and at a specific time concerning the moment of PCI. Promising alternatives to PRECISE-DAPT scores are represented by ARC-HBR and BleeMACS scores, which are validated in large cohorts of patients. More prospective studies are needed in order to establish the relationship between clinical outcomes and the use of such clinical tools.

Supplementary Materials: The following are available online at https://www.mdpi.com/2227-903 2/9/2/148/s1, Table S1: Definitions of bleeding risk scores, Table S2: Comparative discrimination power of bleeding risk scores reported in clinical studies, Table S3: Risk of bias and applicability assessment based on PROBAST checklist.

Author Contributions: Conceptualization, C.B. and L.M.; methodology, C.B. and L.M.; investigation, C.B. and A.B.; writing-original draft preparation, C.B. and A.B.; writing-review and editing, A.B.; supervision, G.T. and A.C. All authors have read and agreed to the published version of the manuscript.

Funding: This research received no external funding.

Conflicts of Interest: The authors declare no conflict of interest. 


\section{References}

1. Palmerini, T.; Biondi-Zoccai, G.; Della Riva, D.; Stettler, C.; Sangiorgi, D.; D’Ascenzo, F.; Kimura, T.; Briguori, C.; Sabatè, M.; Kim, H.S.; et al. Stent thrombosis with drug-eluting and bare-metal stents: Evidence from a comprehensive network meta-analysis. Lancet 2012, 379, 1393-1402. [CrossRef]

2. Claessen, B.E.; Henriques, J.P.; Jaffer, F.A.; Mehran, R.; Piek, J.J.; Dangas, G.D. Stent Thrombosis: A clinical perspective. JACC Cardiovasc. Interv. 2014, 7, 1081-1092. [CrossRef] [PubMed]

3. Watts, T.; Chatterjee, A.; Leesar, M. Stent Thrombosis: Early, Late, and Very Late. In Cardiovascular Thrombus; Topaz, O., Ed.; Academic Press: London, UK, 2018; pp. 217-224.

4. Looser, P.; Kim, L.; Feldman, D. In-Stent Restenosis: Pathophysiology and Treatment. Curr. Treat. Options Cardio Med. 2016, 18, 10. [CrossRef] [PubMed]

5. Kim, B.K.; Hong, M.K.; Shin, D.H.; Nam, C.M.; Kim, J.S.; Ko, Y.G.; Choi, D.; Kang, T.S.; Park, B.E.; Kang, W.C.; et al. A New Strategy for Discontinuation of Dual Antiplatelet Therapy. J. Am. Coll. Cardiol. 2012, 60, 1340-1348. [CrossRef] [PubMed]

6. Hahn, J.Y.; Song, Y.B.; Oh, J.H.; Cho, D.K.; Lee, J.B.; Doh, J.H.; Kim, S.H.; Jeong, J.O.; Bae, J.H.; Kim, B.O.; et al. 6-month versus 12-month or longer dual antiplatelet therapy after percutaneous coronary intervention in patients with acute coronary syndrome (SMART-DATE): A randomised, open-label, non-inferiority trial. Lancet 2018, 391, 1274-1284. [CrossRef]

7. Vranckx, P.; Valgimigli, M.; Jüni, P.; Hamm, C.; Steg, P.G.; Heg, D.; van Es, G.A.; McFadden, E.P.; Onuma, Y.; van Meijeren, C.; et al. Ticagrelor plus aspirin for 1 month, followed by ticagrelor monotherapy for 23 months vs aspirin plus clopidogrel or ticagrelor for 12 months, followed by aspirin monotherapy for 12 months after implantation of a drug-eluting stent: A multicentre, open-label, randomised superiority trial. Lancet 2018, 392, 940-949. [PubMed]

8. Kikkert, W.; Damman, P. Optimal duration of dual antiplatelet therapy for coronary artery disease. Neth. Heart J. 2018, 26, 321-333. [CrossRef] [PubMed]

9. Levine, G.N.; Bates, E.R.; Bittl, J.A.; Brindis, R.G.; Fihn, S.D.; Fleisher, L.A.; Granger, C.B.; Lange, R.A.; Mack, M.J.; Mauri, L.; et al. 2016 ACC/AHA Guideline Focused Update on Duration of Dual Antiplatelet Therapy in Patients with Coronary Artery Disease. J. Am. Coll. Cardiol. 2016, 68, 1082-1115. [CrossRef]

10. Capodanno, D.; Alfonso, F.; Levine, G.N.; Valgimigli, M.; Angiolillo, D.J. ACC/AHA Versus ESC Guidelines on Dual Antiplatelet Therapy. J. Am. Coll. Cardiol. 2018, 72, 2915-2931. [CrossRef]

11. Valgimigli, M.; Bueno, H.; Byrne, R.A.; Collet, J.P.; Costa, F.; Jeppsson, A.; Jüni, P.; Kastrati, A.; Kolh, P.; Mauri, L.; et al. 2017 ESC focused update on dual antiplatelet therapy in coronary artery disease developed in collaboration with EACTS. Eur. Heart J. 2017, 39, 213-260. [CrossRef]

12. Liberati, A.; Altman, D.G.; Tetzlaff, J.; Mulrow, C.; Gøtzsche, P.C.; Ioannidis, J.P.; Clarke, M.; Devereaux, P.J.; Kleijnen, J.; Moher, D. The PRISMA statement for reporting systematic reviews and meta-analyses of studies that evaluate health care interventions: Explanation and elaboration. J. Clin. Epidemiol. 2009, 62, e1-e34. [CrossRef] [PubMed]

13. Moons, K.G.; Wolff, R.F.; Riley, R.D.; Whiting, P.F.; Westwood, M.; Collins, G.S.; Reitsma, J.B.; Kleijnen, J.; Mallett, S. PROBAST: A Tool to Assess Risk of Bias and Applicability of Prediction Model Studies: Explanation and Elaboration. Ann. Intern. Med. 2019, 170, W1-W33. [CrossRef] [PubMed]

14. Choi, S.Y.; Kim, M.H.; Cho, Y.R.; Sung Park, J.; Min Lee, K.; Park, T.H.; Yun, S.C. Performance of PRECISE-DAPT Score for Predicting Bleeding Complication During Dual Antiplatelet Therapy. Circ. Cardiovasc. Interv. 2018, 11, e006837. [CrossRef] [PubMed]

15. Abu-Assi, E.; Raposeiras-Roubin, S.; Cobas-Paz, R.; Caneiro-Queija, B.; Martínez-Reglero, C.; Rodríguez-Rodríguez, J.M.; Baz, A.; Iniguez-Romo, A. Assessing the performance of the PRECISE-DAPT and PARIS risk scores for predicting one-year out-of-hospital bleeding in acute coronary syndrome patients. EuroIntervention 2018, 13, 1914-1922. [CrossRef] [PubMed]

16. Flores-Ríos, X.; Couto-Mallón, D.; Rodríguez-Garrido, J.; García-Guimaraes, M.; Gargallo-Fernández, P.; Piñón-Esteban, P.; Aldama-López, G.; Salgado-Fernández, J.; Calviño-Santos, R.; Vázquez-González, N.; et al. Comparison of the performance of the CRUSADE, ACUITY-HORIZONS, and ACTION bleeding risk scores in STEMI undergoing primary PCI: Insights from a cohort of 1391 patients. Eur. Heart J. Acute Cardiovasc. Care 2012, 2, 19-26. [CrossRef]

17. Ariza-Solé, A.; Sánchez-Elvira, G.; Sánchez-Salado, J.C.; Lorente-Tordera, V.; Salazar-Mendiguchía, J.; Sánchez-Prieto, R.; Romaguera-Torres, R.; Ferreiro-Gutiérrez, J.L.; Gómez-Hospital, J.A.; Cequier-Fillat, A. CRUSADE bleeding risk score validation for ST-segment-elevation myocardial infarction undergoing primary percutaneous coronary intervention. Thromb. Res. 2013, 132, 652-658. [CrossRef]

18. Ueki, Y.; Bär, S.; Losdat, S.; Otsuka, T.; Zanchin, C.; Zanchin, T.; Gragnano, F.; Gargiulo, G.; Siontis, G.C.; Praz, F.; et al. Validation of Bleeding Risk Criteria (ARC-HBR) in Patients Undergoing Percutaneous Coronary Intervention and Comparison with Contemporary Bleeding Risk Scores. EuroIntervention 2020, 16, 371-379. [CrossRef]

19. Cao, D.; Mehran, R.; Dangas, G.; Baber, U.; Sartori, S.; Chandiramani, R.; Stefanini, G.G.; Angiolillo, D.J.; Capodanno, D.; Urban, P.; et al. Validation of the Academic Research Consortium High Bleeding Risk Definition in Contemporary PCI Patients. J. Am. Coll. Cardiol. 2020, 75, 2711-2722. [CrossRef]

20. Song, L.; Guan, C.; Yan, H.; Qiao, S.; Wu, Y.; Yuan, J.; Dou, K.; Yang, Y.; Dangas, G.D.; Xu, B. Validation of contemporary risk scores in predicting coronary thrombotic events and major bleeding in patients with acute coronary syndrome after drug-eluting stent implantations. Catheter. Cardiovasc. Interv. 2018, 91, 573-581. [CrossRef]

21. Ueda, P.; Jernberg, T.; James, S.; Alfredsson, J.; Erlinge, D.; Omerovic, E.; Persson, J.; Ravn-Fischer, A.; Tornvall, P.; Svennblad, B.; et al. External Validation of the DAPT Score in a Nationwide Population. J. Am. Coll. Cardiol. 2018, 72, 1069-1078. [CrossRef] 
22. Costa, F.; van Klaveren, D.; James, S.; Heg, D.; Räber, L.; Feres, F.; Pilgrim, T.; Hong, M.K.; Kim, H.S.; Colombo, A.; et al. Derivation and validation of the predicting bleeding complications in patients undergoing stent implantation and subsequent dual antiplatelet therapy (PRECISE-DAPT) score: A pooled analysis of individual-patient datasets from clinical trials. Lancet 2017, 389, 1025-1034. [CrossRef]

23. Yeh, R.W.; Secemsky, E.A.; Kereiakes, D.J.; Normand, S.L.; Gershlick, A.H.; Cohen, D.J.; Spertus, J.A.; Steg, P.G.; Cutlip, D.E.; Rinaldi, M.J.; et al. Development and Validation of a Prediction Rule for Benefit and Harm of Dual Antiplatelet Therapy Beyond 1 Year After Percutaneous Coronary Intervention. JAMA 2016, 315, 1735-1749. [CrossRef] [PubMed]

24. Baber, U.; Mehran, R.; Giustino, G.; Cohen, D.J.; Henry, T.D.; Sartori, S.; Ariti, C.; Litherland, C.; Dangas, G.; Gibson, C.M.; et al. Coronary Thrombosis and Major Bleeding After PCI With Drug-Eluting Stents. J. Am. Coll. Cardiol. 2016, 67, 2224-2234. [CrossRef] [PubMed]

25. Bianco, M.; D'ascenzo, F.; Roubin, S.R.; Kinnaird, T.; Peyracchia, M.; Ariza-Solé, A.; Cerrato, E.; Manzano-Fernández, S.; Gravinese, C.; Templin, C.; et al. Comparative external validation of the PRECISE-DAPT and PARIS risk scores in 4424 acute coronary syndrome patients treated with prasugrel or ticagrelor. Int. J. Cardiol. 2019, 301, 200-206. [CrossRef] [PubMed]

26. Raposeiras-Roubín, S.; Faxén, J.; Íñiguez-Romo, A.; Henriques, J.P.; D’Ascenzo, F.; Saucedo, J.; Szummer, K.; Jernberg, T.; James, S.K.; Juanatey, J.R.; et al. Development and external validation of a post-discharge bleeding risk score in patients with acute coronary syndrome: The BleeMACS score. Int. J. Cardiol. 2018, 254, 10-15. [CrossRef]

27. Sharma, P.K.; Chhatriwalla, A.K.; Cohen, D.J.; Jang, J.S.; Baweja, P.; Gosch, K.; Jones, P.; Bach, R.G.; Arnold, S.V.; Spertus, J.A. Predicting long-term bleeding after percutaneous coronary intervention. Catheter. Cardiovasc. Interv. 2016, 89, 199-206. [CrossRef]

28. Costa, F.; Tijssen, J.G.; Ariotti, S.; Giatti, S.; Moscarella, E.; Guastaroba, P.; De Palma, R.; Andò, G.; Oreto, G.; Zijlstra, F.; et al. Incremental Value of the CRUSADE, ACUITY, and HAS-BLED Risk Scores for the Prediction of Hemorrhagic Events After Coronary Stent Implantation in Patients Undergoing Long or Short Duration of Dual Antiplatelet Therapy. J. Am. Heart Assoc. 2015, 4, e002524. [CrossRef]

29. Choi, K.H.; Song, Y.B.; Lee, J.M.; Park, T.K.; Yang, J.H.; Choi, J.H.; Choi, S.H.; Oh, J.H.; Cho, D.K.; Lee, J.B.; et al. Clinical Usefulness of PRECISE-DAPT Score for Predicting Bleeding Events in Patients with Acute Coronary Syndrome Undergoing Percutaneous Coronary Intervention, An Analysis From the SMART-DATE Randomized Trial. Circ. Cardiovasc. Interv. 2020, 13, 1-12. [CrossRef]

30. Kawashima, H.; Gao, C.; Takahashi, K.; Tomaniak, M.; Ono, M.; Hara, H.; Wang, R.; Chichareon, P.; Suryapranata, H.; Walsh, S.; et al. Comparative Assessment of Predictive Performance of PRECISE-DAPT, CRUSADE, and ACUITY Scores in Risk Stratifying 30-Day Bleeding Events. Thromb. Haemost. 2020, 120, 1087-1095.

31. Gragnano, F.; Heg, D.; Franzone, A.; McFadden, E.P.; Leonardi, S.; Piccolo, R.; Vranckx, P.; Branca, M.; Serruys, P.W.; Benit, E.; et al. PRECISE-DAPT score for bleeding risk prediction in patients on dual or single antiplatelet regimens: Insights from the GLOBAL LEADERS and GLASSY. Eur. Heart J. Cardiovasc. Pharmacother. 2020, pvaa106. [CrossRef]

32. Garay, A.; Ariza-Solé, A.; Formiga, F.; Raposeiras-Roubín, S.; Abu-Assi, E.; Sánchez-Salado, J.C.; Lorente, V.; Alegre, O.; Henriques, J.P.; D'Ascenzo, F.; et al. Prediction of Post-Discharge Bleeding in Elderly Patients with Acute Coronary Syndromes: Insights from the BleeMACS Registry. Thromb. Haemost. 2018, 118, 929-938. [CrossRef] [PubMed]

33. Subherwal, S.; Bach, R.; Chen, A. Baseline Risk of Major Bleeding in Non-ST-Segment-Elevation Myocardial Infarction. Circulation 2009, 119, 1873-1882. [CrossRef] [PubMed]

34. Mehran, R.; Pocock, S.J.; Nikolsky, E.; Clayton, T.; Dangas, G.D.; Kirtane, A.J.; Parise, H.; Fahy, M.; Manoukian, S.V.; Feit, F.; et al. A Risk Score to Predict Bleeding in Patients with Acute Coronary Syndromes. J. Am. Coll. Cardiol. 2010, 55, 2556-2566. [CrossRef] [PubMed]

35. Mathews, R.; Peterson, E.D.; Chen, A.Y.; Wang, T.Y.; Chin, C.T.; Fonarow, G.C.; Cannon, C.P.; Rumsfeld, J.S.; Roe, M.T.; Alexander, K.P. In-Hospital Major Bleeding During ST-Elevation and Non-ST-Elevation Myocardial Infarction Care: Derivation and Validation of a Model from the ACTION Registry ${ }^{\circledR}$-GWTG ${ }^{\mathrm{TM}}$. Am. J. Cardiol. 2011, 107, 1136-1143. [CrossRef] [PubMed]

36. Pavasini, R.; Maietti, E.; Tonet, E.; Bugani, G.; Tebaldi, M.; Biscaglia, S.; Cimaglia, P.; Serenelli, M.; Ruggiero, R.; Vitali, F.; et al. Bleeding Risk Scores and Scales of Frailty for the Prediction of Haemorrhagic Events in Older Adults with Acute Coronary Syndrome: Insights from the FRASER study. Cardiovasc. Drugs Ther. 2019, 33, 523-532. [CrossRef] [PubMed]

37. Moon, J.Y.; Franchi, F.; Rollini, F.; Angiolillo, D.J. Evolution of Coronary Stent Technology and Implications for Duration of Dual Antiplatelet Therapy. Prog. Cardiovasc. Dis. 2018, 60, 478-490. [CrossRef]

38. Dangas, G.; Baber, U.; Sharma, S.; Giustino, G.; Mehta, S.; Cohen, D.; Angiolillo, D.; Sartori, S.; Chandiramani, R.; Briguori, C.; et al. Ticagrelor With Aspirin or Alone After Complex PCI: The TWILIGHT-COMPLEX Analysis. J. Am. Coll. Cardiol. 2020, 75, 2414-2424. [CrossRef]

39. Hahn, J.Y.; Song, Y.B.; Oh, J.H.; Chun, W.J.; Park, Y.H.; Jang, W.J.; Im, E.S.; Jeong, J.O.; Cho, B.R.; Oh, S.K.; et al. Effect of P2Y12 Inhibitor Monotherapy vs Dual Antiplatelet Therapy on Cardiovascular Events in Patients Undergoing Percutaneous Coronary Intervention. JAMA 2019, 321, 2428-2437. [CrossRef]

40. Watanabe, H.; Domei, T.; Morimoto, T.; Natsuaki, M.; Shiomi, H.; Toyota, T.; Ohya, M.; Suwa, S.; Takagi, K.; Nanasato, M.; et al. Effect of 1-Month Dual Antiplatelet Therapy Followed by Clopidogrel vs 12-Month Dual Antiplatelet Therapy on Cardiovascular and Bleeding Events in Patients Receiving PCI. JAMA 2019, 321, 2414. [CrossRef]

41. Feres, F.; Costa, R.A.; Abizaid, A.; Leon, M.B.; Marin-Neto, J.A.; Botelho, R.V.; King, S.B.; Negoita, M.; Liu, M.; de Paula, J.E.; et al. Three vs Twelve Months of Dual Antiplatelet Therapy After Zotarolimus-Eluting Stents. JAMA 2013, 310, 2510-2522. [CrossRef] 